\title{
Vehicle Inspection Policy and Emission Analysis in Kuwait
}

\author{
Sharaf Al Kheder \\ sharaf.alkehder@ku.edu.kw \\ Civil Engineering Department, College of Engineering and Petroleum, Kuwait University, Kuwait
}

Fahad Al Rukaibi

f.alrukaibi@ku.edu.kw

Civil Engineering Department, College of Engineering and Petroleum, Kuwait University, Kuwait

\author{
Ahmad Aiash \\ ahmad.aiash@grad.ku.edu.kw \\ Civil Engineering Department, College of Engineering and Petroleum, Kuwait University, Kuwait
}

\begin{abstract}
Technical vehicle inspection centers are widespread in Kuwait. All vehicles should pass the test every two years if not older than six years or every one-year for other vehicles. This study provided an insight into the data collected from test centers and the emission test utilized in Kuwait. Data were collected from tests centers in the six governorates. 196 vehicles were tested but only 152 vehicles were utilized for CO emission violation and 157 vehicles for $\mathrm{HC}$ emission violation. European standards were selected as limits for emission violation. Independent variables included place of vehicle manufacture, vehicle's age, and odometer reading. A multinomial logit model was used to identify the significant predictors and to determine the correlation between dependent and independent variables. ANN was employed to compare prediction estimates of neural network and multinomial logit. The findings showed that the place of vehicle's manufacture, vehicle's age, and odometer reading were significant regarding violating emission standards of CO. Asian vehicles, vehicles with more than 150,000 km mileage, and vehicles older than 15 years had a higher probability of failing CO test as compared to place of manufacture. In contrast, the odometer reading was the only significant indicator for vehicles that have failed $\mathrm{HC}$ test especially those with 150,000 km odometer reading.
\end{abstract}

Keywords: Inspection test; Emission data; Analysis; Kuwait

\section{INTRODUCTION}

"The vehicle technical inspection can be defined as a process that is necessitated by governments in different countries, so that the vehicle can be scrutinized to conform with legalized standards" (Al-Kandari, 2017). "This process is sometimes required periodically or when the ownership of the vehicle is transferred to someone else" (Wolfe and O'Day, 1985). The reasons for making vehicle technical inspection as a compulsory test is that pollution can be lessened and set of other standards of the vehicle can be checked (Taneerananon et al., 2005).

Many developed countries are using vehicle technical inspection and maintenance programs to identify high-polluting vehicles. They have also set a procedure to selectively target vehicles that most likely happen to be pollution laws' violators. Most significant 
parameters behind the high- pollutants emissions from vehicles were identified as vehicle age, vehicle manufacturer, number of engine cylinders, odometer reading, and whether or not oxygenated fuels were in use (Washburn et al., 2001).

Furthermore, it is worth mentioning that vehicle defects can be considered as one of the contributing factors affecting the environmental quality, even though the scale of the issue is less prominent than human behavior or road environmental factors. However, this technical problem may find a more direct and easier effective solution compared to human behavioral issues. A previous study conducted in Malaysia discussed common vehicle defects contributing to traffic accidents and affecting environment quality. They used a periodical technical inspection database as a basis for their study and determined the common failures affecting the environment and road safety (Solah et al., 2017).

(Millard et al., 2017) "provided an extensive review of the international experience in using vehicles' technical inspection information". Their work investigated the possibility of modelling the relationship between car inspection information and vehicle usage \& ownership, energy consumption and vehicle's emission. Their work also consisted of reviewing the international literature on technical inspection and a survey to cognize the international experience in this field. The survey focused on checking odometer readings availability, type of data formatting, car owners' data availability, and data usage. Similar international literature review on technical inspection data can be seen also in the work of (Cairns et al., 2014) and (Chatterton and Anable, 2016).

Reviewing the international literature revealed huge experience in using vehicle technical inspection data for the above-mentioned applications and especially in vehicle emissions' modelling. (Li et al., 2017) performed a study to investigate the social and spatial effects of transforming the private vehicle fleet in Brisbane, Australia. They studied the continuous change in vehicle fleet efficiency (VEF) and investigated their socio-spatial patterns. They found that inner urban locations witnessed higher rate of VFE change. They related this change to the reduction in fuel consumption through adopting a stronger policy that encourages ownership of fuel-efficient cars, which in return will reduce emissions. In France, a strong periodical car inspection system is being implemented that continuously tests the proper functioning of cars' emissions control devices. In 1994, a motivation program for replacing cars with high emission rates was proposed. Yamamoto et al. (2004) examined the effect of the inspection program and the scrappage's fund on cars' transaction timings through building a hazard-based duration model of the household car transaction behaviour. It was shown that upon the availability of scrappage fund, the conditional probability of replacing a $10+$ old car had increased by $20 \%$.

In Mexico (Riveros et al., 2002), (I/M) data provided a valuable emission database, carbon monoxide (CO) and Hydrocarbon (HC) emission measurements for about a million vehicles were collected, from Mexico City. The results of analyzing such a big database were helpful in checking anti-pollutant strategies and as a performance index of car-manufacturing quality. In Sweden, Bastian and Börjesson (2015) showed that GDP and petrol cost clarified majority of the tendencies in the travelled vehicle distances. They measured the total distance travelled for the period from 2002 to 2012 by using the distance meter readings taken from the vehicle inspection tests. Results indicated a considerable difference in elasticities among municipalities according to 
public transport supply, population density, percent of foreign-born populations and the average income. In UAE, Selim et al (2011) reviewed the mechanical and environmental car inspection programs at different test centers. The results indicated a serious variation between different centers in the country concerning adherence to test regulations and ways of inspection.

In the USA, Cook et al. (2015) used a database of more than 20 million cars in California to stem estimations of VMT and fuel consumption to inspect the spatial spreading of influences for the raise in fuel price besides the effects of applying alternative indicators for policy assessment. Results indicated that the distributions of VMT and fuel consumption varied considerably between different transport regions. Another study done in California Salon et al. (2014) reported on the household car greenhouse gas emissions inventories for eight cities between 2000 and 2005.

Emissions estimations were analyzed and linked to the certified inventory estimations. Binder et al. (2014) examined the relative effect of car and household features on emissions failures in Atlanta, Georgia through connecting the emissions inspection data to a targeted database with info on car owners. Count and hurdle models were used to forecast car emissions failures. Results indicated a clear connection between sociodemographic features and emissions failures. Another study in Massachusetts Ferreira et al. (2012) investigated the relation between costs of crash and the yearly VMT for 3 million passengers' car years of insurance exposure during 2006. Modelling the driver response to pay-as-you-drive insurance indicated that the aggregate VMT and private passenger car greenhouse gas emissions in Massachusetts would fall by 5.0 to $9.5 \%$.

During urbanization, an increase in the numbers of vehicles can be witnessed, which deteriorates air quality. Emission standards became more stringent recently. Inspection programs are increasingly needed to examine vehicles periodically to check their compliance with emission standards. Although traditional technical vehicle inspection programs helped in improving air quality, their suitability had been criticized for many years (Harrington et al., 2000) (Bin, 2003) (Bishop and Stedman, 2008). One of the recent studies Hubbard, (2007), Schifter et al. (2003) showed that the actual number of vehicle on-road emissions were much higher than those measured during emission inspections.

\section{DATA DESCRIPTION}

The data that were utilized in this study were collected from the six governmental inspection centers in the six governorates of Kuwait including Mubarak Al-Kabeer Governorate, Hawally Governorate, Al-Jahra Governorate, Al Frawaniya Governorate, Al Asima Governorate, and Al Ahmadi Governorate. The data collection was accomplished with the assistance of inspector specialists in 2012 to randomly inspect various types of vehicles with a focus on passenger vehicles. The inspection test evaluated the type and the brand of the vehicle, the date when the vehicle was manufactured, odometer reading, brake condition, tire condition, windshield, fuel tank cap, mirrors, smoke from the exhausts, and emissions data. The data collection started on 1 April 2012 and ended on 26 April 2012. The average daily inspected vehicles in most of the urban inspection test centers were 400 to 500 vehicles per day while the rural centers had between 300 to 400 vehicles per day. As a result, a random sample of 196 different vehicles were inspected 
and tested to measure all the previously mentioned aspects. The data were separated into two divisions including vehicles that violated the European test emission standards for the $\mathrm{CO}$ gas and the vehicles that violated the same standards but for Hydrocarbon (HC) gas. This is the main reason behind the low number of tested vehicles that were studied in this paper, as only vehicles with specific number of $\mathrm{CO}$ and $\mathrm{HC}$ violations were included. This, also, can be justified from the number of days that were used to collect this type of data. In Middle east, in general, and in Kuwait, in particular, this type of data is usually hard to be collected from an accessible data base. Then, the data was checked closely to determine if there are any missing values. Due to the undetermined or blanked answers, 152 passenger vehicles were chosen to determine three main factors that may be associated with the increasing emissions volume of $\mathrm{CO}$ from the vehicles' exhausts. For the HC, a total of 157 passenger vehicles were utilized for the analysis section of the study. A few numbers of non-passenger vehicles were inspected and tested and part of those vehicles the description data was missing about. Consequently, only passenger vehicles that had a completed test data, used gasoline fuel, and failed the European emission test standards were chosen for this study.

Table 1 and 2 show the overall statistics of the three potential factors that are associated with the increasing emissions volume. Models of the vehicles were classified into three categories including European manufactured vehicles; American manufactured vehicles; and Asian manufactured vehicles. This categorization was established to measure the performance of cars in general, and to establish a preidentified target when the test holders are conducting the test so they can concentrate more on these vehicles. The number of observed vehicles that were considered as European were the lowest in both Table 1 and 2. However, Asian-made vehicles were the highest that violated the standard of emissions for both $\mathrm{CO}$ and $\mathrm{HC}$. Also, American vehicles ranked second in emitting $\mathrm{CO}$ and $\mathrm{HC}$ in high volumes. The age of the vehicle was another chosen predictor to identify its impact on the emissions' rate of $\mathrm{CO}$ and $\mathrm{HC}$. The collected sample was fairly distributed between the four categories of vehicle age, which includes vehicles that were 1 to 5 years old, 6 to 10 years old, vehicles between 11 to 15 years old, and vehicles older than 15 years.

Table 1: Descriptive statistics of independent variables related to CO

\begin{tabular}{|l|l|c|c|c|c|c|}
\hline Variable & \multirow{2}{*}{ Category } & \multirow{2}{*}{ Abbreviation } & \multicolumn{3}{|c|}{ CO g/km } & Total \\
\cline { 4 - 6 } & & & 1 to 4.5 & 4.6 to 16.5 & more than16.5 & \\
\hline Model & European vehicle & MOD1 & 6 & 9 & 2 & 17 \\
\hline & American vehicle & MOD2 & 6 & 20 & 10 & 36 \\
\hline & Asian vehicle & MOD3 & 14 & 50 & 35 & 99 \\
\hline Age & 1 to 5 years & AGE1 & 9 & 20 & 2 & 31 \\
\hline & 6 to 10 years & AGE2 & 9 & 31 & 10 & 50 \\
\hline & 11 to 15 years & AGE3 & 4 & 20 & 18 & 42 \\
\hline & more than 15 years & AGE4 & 4 & 8 & 17 & 29 \\
\hline $\begin{array}{l}\text { Odometer } \\
\text { reading }\end{array}$ & 0 to $50,000 \mathrm{~km}$ & ODO1 & 5 & 7 & 3 & 15 \\
\hline & & & & & & 5 \\
\hline & 50,001 to $150,000 \mathrm{~km}$ & ODO2 & 11 & 41 & 6 & 58 \\
\hline & more than $150,000 \mathrm{~km}$ & ODO3 & 10 & 31 & 38 & 79 \\
\hline
\end{tabular}


Table 2: Descriptive statistics of independent variables related to $\mathrm{HC}$

\begin{tabular}{|l|l|c|c|c|c|c|}
\hline Variable & \multirow{2}{*}{ Category } & \multirow{2}{*}{ Abbreviation } & \multicolumn{3}{|c|}{ HC gm/km } & Total \\
\cline { 4 - 6 } & & & 1 to 4.5 & 4.6 to 16.5 & more than16.5 & \\
\hline Model & European vehicle & MOD1 & 11 & 2 & 5 & 18 \\
\hline & American vehicle & MOD2 & 18 & 10 & 10 & 38 \\
\hline & Asian vehicle & MOD3 & 58 & 27 & 16 & 101 \\
\hline Age & 1 to 5 years & AGE1 & 18 & 6 & 2 & 26 \\
\hline & 6 to 10 years & AGE2 & 26 & 13 & 9 & 48 \\
\hline & 11 to 15 years & AGE3 & 29 & 12 & 10 & 51 \\
\hline & more than 15 years & AGE4 & 14 & 8 & 10 & 32 \\
\hline $\begin{array}{l}\text { Odometer } \\
\text { reading }\end{array}$ & 0 to $50,000 \mathrm{~km}$ & ODO1 & 9 & 4 & 3 & 16 \\
\hline & 50,001 to $150,000 \mathrm{~km}$ & ODO2 & 45 & 11 & 4 & 60 \\
\hline & more than $150,000 \mathrm{~km}$ & ODO3 & 33 & 24 & 24 & 81 \\
\hline
\end{tabular}

\section{METHODOLOGY}

\subsection{Multinomial logit regression}

A multicollinearity was tested among the predictors to evaluate the correlations between them. Consequently, a multicollinearity test was performed for both emission cases. The average variance inflation factor (VIF) was 1.158 and 1.078 for CO emission, and $\mathrm{HC}$ emission variables respectively. These results show that there are no multicollinearity issues. Additionally, multinomial logit regression does not assume normality, linearity, or homoscedasticity. As a result, multinomial logit regression was chosen in this study to determine the correlations between the independent variables and the dependent variables.

For the multinomial logit equation as per Ma et al. (2014) and AlKheder et al. (2019), each one of the two dependent variables was assigned to y. For $\mathrm{CO}$, the interval from 1 to $4.5 \mathrm{gm} / \mathrm{km}$ was assigned to $\mathrm{y}=1,4.6$ to $16.5 \mathrm{gm} / \mathrm{km}$ was assigned to $\mathrm{y}=2$, and lastly the $\mathrm{CO}$ emissions that were higher than $16.5 \mathrm{gm} / \mathrm{km}$ was assigned to $\mathrm{y}=3$, which was chosen as the reference level in this study. Then $y=1$ and $y=2$ were compared to $y=3$. Similarly, for $\mathrm{HC}$, the interval from 0.100 to $0.300 \mathrm{gm} / \mathrm{km}$ was assigned to $\mathrm{y}=1,0.301$ to 0.450 $\mathrm{gm} / \mathrm{km}$ was assigned to $\mathrm{y}=2$, and $\mathrm{HC}$ emissions that were higher than $0.450 \mathrm{gm} / \mathrm{km}$ was assigned to $y=3$, which was chosen as the base level. Then $y=1$ and $y=2$ were compared to $\mathrm{y}=3$. The $\mathrm{y}=1$ and $\mathrm{y}=2$ logit regression functions were as follows:

$$
\begin{aligned}
& \operatorname{logit}\left(p_{1}\right)=\ln \left(\frac{p(y=1 \mid x)}{p(y=3 \mid x)}\right)=\alpha_{1}+\sum_{i=1}^{m} \beta_{1 i} x_{i} \\
& \operatorname{logit}\left(p_{2}\right)=\ln \left(\frac{p(y=2 \mid x)}{p(y=3 \mid x)}\right)=\alpha_{2}+\sum_{i=1}^{m} \beta_{2 i} x_{i}
\end{aligned}
$$

For both (1) and (2) equations, the value of the $i$ th predictor is $x_{i}$, the intercept of the first logit function (1) is $\alpha_{1}$, and the intercept for the second logit function (2) is $\alpha_{2} . m$ is representing the number of variables in both equations (1) and (2). The corresponding coefficient of the first logit function (1) is $\beta_{1}$ and the corresponding coefficient is $\beta_{2}$ for 
the second logit function (2). The condition probability of $k$ th outcome category is:

$$
p(y=k \mid x)=\frac{\exp \left(\alpha_{k}+\sum_{i=1}^{m} \beta_{k i} x_{i}\right)}{1+\sum_{k=1}^{K-1}\left(\alpha_{k}+\sum_{i=1}^{m} \beta_{k i} x_{i}\right)}
$$

The intercept of the $k$ th logit function (3) is $\alpha_{K}$, The corresponding coefficient of the $k$ th logit function (3) is $\beta_{k i}$, and the number of outcome categories is $K$.

\subsection{Multinomial logit regression results}

\subsubsection{CO results}

Table 3 shows the maximum likelihood ratios for the independent variables related to $\mathrm{CO}$ gas with different volumes. The results show that all independent variables including the model, age of the vehicle, and odometer reading were found to be significant variables as their p-values were less than 0.05 . As a result, all factors were included in the final model.

Table 3: Maximum-likelihood estimations of CO

\begin{tabular}{|c|c|c|c|c|c|}
\hline Variable & Abbreviation & $\begin{array}{c}-\mathbf{2} \text { Log Likelihood } \\
\text { of Reduced Model }\end{array}$ & Chi-Square & $\begin{array}{c}\text { Degree of } \\
\text { freedom }\end{array}$ & P-value \\
\hline Model & MOD (Base: MOD3) & 105.258 & 12.977 & 4 & 0.011 \\
\hline Age & AGE (Base: AGE4) & 113.298 & 21.017 & 6 & 0.002 \\
\hline Odometer reading & ODO (Base: ODO3) & 104.727 & 12.446 & 4 & 0.014 \\
\hline
\end{tabular}

Table 4 shows the results after applying the multinomial logit regression for the significant variables. European vehicles were found to be a significant variable in both the first and second set with a positive coefficient in table 4 compared to the reference level, which was Asian vehicles. This indicates that Asian vehicles had a higher probability of involving in emissions violations regarding $\mathrm{CO}$ gas compared to European vehicles and related to European standards. Vehicles that were 1 to 5 years old were found to be a significant factor with a positive coefficient in the first and second set compared to vehicles that were older than 15 years old, which was the base level. This indicates that vehicles that were older than 15 years were associated with higher degree of emitting $\mathrm{CO}$ emissions. For vehicles that were between 5 to 15 years old, were found to be a significant factor in the first and second set with a positive coefficient compared to the reference level indicating that vehicles older than 15 years had higher probabilities in emitting $\mathrm{CO}$ gas higher than the standard limits. Vehicles that were between 10 to 15 years old were found to be significant in the last set with a positive coefficient compared to the base category indicating that vehicles older than 15 years had higher chances in violating $\mathrm{CO}$ emissions standards. Lastly, vehicles with more than $50,001 \mathrm{~km}$ but less than $150,000 \mathrm{~km}$ were found to be a significant factor in the second set with a positive coefficient compared to the reference level. This indicates that vehicles with more than $150,000 \mathrm{~km}$ had higher probability of failing the $\mathrm{CO}$ emission test standards. 
Table 4: Multinomial logit regression model for $\mathrm{CO}$

\begin{tabular}{|c|c|c|c|c|c|}
\hline Variable & Coefficient & Standard Error & Wald Chi-square test & P-value & Odds ratio \\
\hline \multicolumn{7}{|c|}{1 to $4.5 \mathrm{gm} / \mathrm{km}$ vs more than $16.5 \mathrm{gm} / \mathrm{km}$} \\
\hline Intercept & -3.051 & 0.836 & 13.331 & 0.000 & \\
\hline MOD1 & 3.305 & 1.062 & 9.677 & 0.002 & 27.243 \\
\hline AGE1 & 3.291 & 1.164 & 7.987 & 0.005 & 26.860 \\
\hline AGE2 & 2.391 & 0.907 & 6.952 & 0.008 & 10.923 \\
\hline \multicolumn{7}{|c|}{4.6 to $16.5 \mathrm{gm} / \mathrm{km}$ vs more than $16.5 \mathrm{gm} / \mathrm{km}$} \\
\hline Intercept & -1.952 & 0.618 & 9.967 & 0.002 & \\
\hline MOD1 & 2.301 & 0.973 & 5.598 & 0.018 & 9.988 \\
\hline AGE1 & 2.777 & 0.961 & 8.347 & 0.004 & 16.066 \\
\hline AGE2 & 2.315 & 0.674 & 11.81 & 0.001 & 10.122 \\
\hline AGE3 & 1.694 & 0.675 & 6.308 & 0.012 & 5.442 \\
\hline ODO2 & 1.839 & 0.594 & 9.596 & 0.002 & 6.293 \\
\hline
\end{tabular}

\subsection{2 $\mathrm{HC}$ results}

Table 5 shows the results of the maximum likelihood tests for $\mathrm{HC}$ emissions. Only odometer reading was found to be a significant variable. Consequently, other independent variables were excluded and only odometer reading was included in the multinomial logit regression model for $\mathrm{HC}$ gas. In table 6, the results show that vehicles with a mileage between 50,001 to 100,000 kilometres were found to be a significant factor in affecting the vehicle to emit $\mathrm{HC}$ gas in higher volumes in the first set with a positive coefficient compared to the reference level, which was vehicles with more than 100,000 kilometres. This indicates that vehicles that had travelled more than 100,000 kilometres had a higher probability of violating the European standards compared to vehicles with 50,001 to 100,000 kilometres mileage.

Table 5: Maximum likelihood estimations for $\mathrm{HC}$

\begin{tabular}{|c|c|c|c|c|c|}
\hline Variable & Abbreviation & $\begin{array}{c}-2 \text { Log Likelihood of } \\
\text { Reduced Model }\end{array}$ & Chi-Square & $\begin{array}{c}\text { Degree of } \\
\text { freedom }\end{array}$ & P-value \\
\hline Model & MOD (Base: MOD3) & 93.343 & 5.765 & 4 & 0.217 \\
\hline Age & AGE (Base: AGE4) & 89.715 & 2.137 & 4 & 0.711 \\
\hline $\begin{array}{c}\text { Odometer } \\
\text { reading }\end{array}$ & ODO (Base: ODO3) & 104.240 & 16.662 & 4 & 0.002 \\
\hline
\end{tabular}

Table 6: Multinomial logit regression for $\mathrm{HC}$

\begin{tabular}{|c|c|c|c|c|c|}
\hline Variable & Coefficient & $\begin{array}{c}\text { Standard } \\
\text { Error }\end{array}$ & $\begin{array}{c}\text { Wald Chi- } \\
\text { square test }\end{array}$ & P-value & Odds ratio \\
\hline \multicolumn{7}{|c|}{} \\
\hline Intercept & 0.100 to $0.300 \mathrm{gm} / \mathrm{km}$ vs more than $0.450 \mathrm{gm} / \mathrm{km}$ \\
\hline ODO2 & 0.318 & 0.268 & 1.409 & 0.235 & \\
\hline
\end{tabular}




\section{CONCLUSION}

This study attempts to improve the technical inspection standards in Kuwait by preidentifying the most polluting vehicles that were emitting harmful gases including carbon monoxides and hydrocarbons. This can help in lessening air-pollution and ameliorate the quality of air. Moreover, the cost of performing the inspection test is mainly accomplished by a governmental sector related to the Ministry of Interior in Kuwait. Special inspectors and public facilities were only utilized for this purpose. Moreover, the time that is wasted due to the long hours required to perform the test, due to the big number of vehicles that need to be tested, is considerably high. This is happening as vehicles to be tested are not pre-identified especially for the emission test as this test is performed randomly or due to visible exhaust smoke from the tested vehicle. Time and money consumed can be both reduced by targeting the most polluting vehicles, thus more efficient tests can be performed.

As a result, a multinomial logit regression was applied so that the correlations between the potential factors associated with the increasing carbon monoxides and hydrocarbons emissions are determined. Three factors were included in this study according to the availability of the data including vehicle manufacture origin, vehicle age, and the odometer reading. Carbon monoxides and hydrocarbons were the dependent variables due to their harmful impact on the air quality. The lack of clear systematic procedures to determine whether the vehicle failed the emission test or passed the test was the reason for following the European standards in determining the failure criteria. For carbon monoxides, all three independent variables were found to be significant in increasing the emission volume. Asian vehicles were found to be the majority of car types in violating the standards compared to European vehicles. The age of vehicle was another significant factor. Vehicles older than 15 years had a higher probability of emitting CO in high volumes, which violates the standards compared to other vehicle categories that were less than 15 years old. Additionally, vehicles with more than 150,000 km mileage were more likely to emit $\mathrm{CO}$ emissions higher than the standard limits compared to vehicles with a mileage less than $150,000 \mathrm{~km}$. For hydrocarbons, only the odometer reading was the significant variable in affecting the emissions volume. Similar to CO results, vehicles that had a reading of more than $150,000 \mathrm{~km}$ on the odometer had higher probability to fail the test according to the standards.

\section{ACKNOWLEDGEMENT}

The Authors would like to thank Kuwait Foundation for the Advancement of Sciences (KFAS) for their generous support.

\section{REFERENCES}

Al-Kandari, M. A. (2017). Legal guide for technical inspection. National Library of Kuwait, Kuwait.

AlKheder, S., AlRukaib, F. \& Aiash, A. (2019). Drivers' response to variable message signs

(VMS) in Kuwait, Cognition, Technology \& Work, pp. 1-15, 2019.

Bastian, A. \& Börjesson, M. (2015). Peak car? Drivers of the recent decline in Swedish car use, 
Transport Policy, 42, pp. 94-102.

Bin, O. (2003). A logit analysis of vehicle emissions using inspection and maintenance testing data, Transportation Research Part D: Transport and Environment, Vol. 8, No. 3, pp. 215227.

Binder, S., Macfarlane, G.S., Garrow, L.A. \& Bierlaire, M. (2014). Associations among household characteristics, vehicle characteristics and emissions failures: An application of targeted marketing data, Transportation Research Part A: Policy and Practice, 59, pp. 122-133.

Bishop, G. A. \& Stedman, D. H. (2008). A decade of on-road emissions measurements, Enviromental Science \& Technology, Vol. 42, No. 5, pp. 1651-1656.

Cairns, S., Rahman, S., Anable, J., Chatterton, T. \& Wilson, R.E. (2014). Vehicle inspections from safety device to climate change tool, MOT Project Working Paper MIS018.

Chatterton, T. \& Anable, J. (2016). Vehicle odometers and other novel methods of examining car ownership and usage (American Association of Geographers Annual Meeting), San Francisco.

Cook, J. A., Sanchirico, J. N., Salon, D. \& Williams, J. (2015). Empirical distributions of vehicle use and fuel efficiency across space: Implications of asymmetry for measuring policy incidence, Transportation Research Part A: Policy and Practice, 78: 187-99.

Ferreira, J. \& Minikel, E. (2012). Measuring per mile risk for pay-as-you-drive Automobile Insurance, ITransportation Research Record, 2297, pp. 97-103.

Harrington, W., McConnell V. \& Ando, A. (2000). Are vehicle emission inspection programs living up to expectations?, Transportation Research Part D: Transport and Environment, Vol. 5, No. 3, pp. 153-172.

Hubbard, T. N. (2007). Using inspection and maintenance programs to regulate vehicle emissions, Contemporary Economic Policy, Vol. 15, No. 2, pp. 52-62.

Li, T., Sipe, N. \& Dodson, J. (2017). Social and spatial effects of transforming the private vehicle fleet in Brisbane, Australia, Transportation Research Part D: Transport and Environment, 51, pp. 43-52.

Ma, Z., Shao, C., Song, Y. \& Chen, J. (2014). Driver response to information provided by variable message signs in Beijing, Transportation Research Part F: Traffic Psychology and Behaviour, Vol. 26, No. Part A, pp. 199-209.

Millard, K., Cairns, S., Beaumont, C., Anable, J., Chatterton T. \& Wilson, R.E. (2017). International experience of collecting and analysing technical inspection data for private cars, Published Project Report PPR847, MOT research project (UKRC Energy Programme/EPSRC), TRL Limited (TRL).

Riveros, H., Cabrera, E. \& Ovalle, P. (2002). Vehicle inspection and maintenance, and air pollution in Mexico City, Transportation Research Part D. 7(1), pp. 72-80.

Salon, D., Cook, J. \& Williams, J. (2014). Household vehicle Carbon emissions in California cities, Transportation Research Board: 93rd Annual Meeting (No. 14-0630).

Schifter, I., Díaz, L., Durán, J., Guzmán, E., Chávez, O. \& López-Salinas, E. (2007). Remote sensing study of emissions from motor vehicles in the metropolitan area of Mexico City, Enviromental Science \& Technology, Vol. 37, No. 2, p. 395-401.

Selim, M. Y. E., Maraqa, M. A., Hawas, Y. E. \& Mohamed, A.M.O. (2011). Assessment of vehicle inspection and emission standards in the United Arab Emirates, In Transportation Research Part D: Transport and Environment, 16(4), pp. 332-334.

Solah, M. S., Hamzah, A., Ariffin, A. H., Paiman, N. F., Abdul Hamid, I., Abdul Wahab, M. A. F., Mohd Jawi, Z. \& Osman, M. R. (2017). Private Vehicle roadworthiness in Malaysia from 
the vehicle inspection perspective, Journal of the Society of Automotive Engineers Malaysia, Vol. 1, No. 3, pp. 2550-2239

Taneerananon, P., Chanwannnakul, T., Suanpaga, V., Khompratya, T., Kronprasert, N. \& Tanaboriboon, Y. (2005). An evaluation of the effectiveness of private vehicle inspection process in Thailand, Journal of the Eastern Asia Society for Transportation Studies, Vol. 6, pp. 3482-3496.

Washburn, S., Seet, J. \& Mannering, F. (2001). Statistical modeling of vehicle emissions from inspection/maintenance testing data: an exploratory analysis, Transportation Research Part D: Transport and Environment, Vol. 6, No. 1, pp. 21-36.

Wolfe, A. C. \& O’Day, J. (1985). Cost-effectiveness of periodic motor vehicle inspection, University of Michigan. University of Michigan, Michigan.

Yamamoto, T., Madre, J. L. \& Kitamura, R. (2004). An analysis of the effects of French vehicle inspection program and grant for scrappage on household vehicle transaction, Transportation Research Part B, 38(10), pp. 905-926. 